\title{
PENGEMBANGAN TES KEMAMPUAN KOMUNIKASI MATEMATIS PADA MATERI SISTEM PERSAMAAN LINEAR UNTUK MAHASISWA CALON GURU MATEMATIKA
}

\author{
Amrina Rizta ${ }^{*}$, Luvi Antari ${ }^{2}$ \\ ${ }^{1,2}$ Pendidikan Matematika, Universitas Muhammadiyah Palembang \\ E-mail: $\quad$ amrina_rizta@um-palembang.ac.id ${ }^{\left.{ }^{*}\right)}$ \\ luviantari@gmail.com $^{2)}$
}

Received 4 August 2018; Received in revised form 19 September 2018; Accepted 24 September 2018

\begin{abstract}
This study aims to develop instrument for measuring mathematical communication skills of student prospective mathematics teacher. Development of this instrument used ADDIE model that has five steps: analyze, design, develop, implement, and evaluate, but in this study only done until the develop step. This instrumen test consists of five items essay test. Validation of this test performed twice that is content validation and empirical validation. The result content validity and emperical validation is all of item valid. After that, to know the reliability, the differentiating power, and the difficulty of item in the instrument conducted trials. The result show that valid items have reliabity coefficient Alpha Cronbach is 0,708, the diffrentiating power of item is enough and the difficulty of item in middle categorized. This result shows that the instrument of mathematical communication test that has been developed valid and reliable. So, the instrument can be used as an instrument of data collection research.
\end{abstract}

Keywords: Development; Mathematical Communication Skills; Student; Test.

\section{PENDAHULUAN}

Matematika merupakan salah satu mata pelajaran yang penting, sehingga sejak usia dini matematika sudah dikenalkan ke peserta didik baik secara formal maupun non-formal. Salah satu kemampuan yang penting untuk diasah peserta didik dalam pembelajaran matematika adalah kemampuan komunikasi matematis. Pentingnya kemampuan tersebut dapat dilihat pada salah satu tujuan pendidikan matematika dalam Permendiknas Nomor 22 Tahun 2016 yaitu agar peserta didik memiliki kemampuan mengkomunikasikan gagasan dengan simbol, tabel, grafik atau diagram untuk mempelajari keadaan atau masalah. Selain itu, prinsip-prinsip dan standar NCTM juga menekankan pada kemampuan komunikasi sebagai bagian penting dari matematika dan pendidikan matematika.

\footnotetext{
* Corresponding author. Address: Department of Mathematics Education, Muhammadiyah University of Palembang, Indonesia

E-mail address: amrina_rizta@um-palembang.ac.id
}

Temuan dari penelitian Uptegrove (2015) diketahui bahwa untuk memahami gagasan matematika dapat menggunakan berbagai representasi berupa model fisik, gambar, diagram, kata-kata yang diucapkan, dan simbol matematika. berdasarkan temuan penelitian tersebut dapat disimpulkan bahwa untuk memahami gagasan matematika diperlukan kemampuan komunikasi matematis yang baik. Melalui komunikasi sebuah ide menjadi objek refleksi, perbaikan, diskusi, dan perubahan. Proses inilah yang membantu membangun makna, menetapkan ide, dan menjadikan ide tersebut berlaku umum (Yuniarti, 2014).

Kemampuan komunikasi matematis dapat mengubah sudut pandang siswa tentang matematika. Hal ini sangat dimungkinkan jika calon guru matematika dapat memberikan gambaran yang wajar tentang matematika. Menurut Widjajanti \& Wahyudin (2010) gambaran siswa yang keliru mengenai matematika dipengaruhi oleh 
pengalaman mereka dalam belajar matematika. Sehingga, bagaimana cara guru matematika dalam mengkomunikasi-kan konsep, struktur, teorema, atau rumus matematis kepada siswa akan berpengaruh terhadap gambaran siswa tentang matematika. Son (2015) mengungkapkan bahwa kemampuan komunikasi matematis sangatlah penting bagi seorang guru matematika dalam perannya sebagai fasilitator dan mediator dalam belajar. Guru dapat mengubah pandangan matematika yang sulit dan sangat abstrak bagi siswa dengan cara penyampaian yang benar. Oleh karena itu, calon guru matematika harus mampu memanfaatkan waktu saat dibangku kuliah untuk melatih kemampuan komulnikasi matematisnya baik secara lisan maupun tulisan.

Rendahnya kemampuan komunikasi matematis mahasiswa saat ini terlihat dari kemampuan mereka dalam menuliskan ide-ide matematika maupun alasan terhadap jawaban yang mereka ungkapkan. Hal yang sama juga diungkapkan oleh Nayazik \& Arie (2017) bahwa rendahnya kemampuan komunikasi matematis mahasiswa calon guru matematika ditunjukkan saat mereka mengkomunikasikan gagasannya dalam bentuk tulisan, ketika ada permasalahan yang disajikan dalam bentuk soal cerita mereka masih kebingungan untuk menyelesaikannya serta kesulitan dalam membuat model matematika.

Begitu pula dengan kemampuan komunikasi matematis mahasiswa calon guru matematika di UM Palembang. Hasil pengamatan selama proses pembelajaran pada mahasiswa yang mengikuti mata kuliah aljabar linear elementer ditemukan bahwa mahasiswa masih kesulitan dalam menginterpretasikan ide-ide matematika dalam bentuk gambar, ataupun model matematika dari permasalahan yang diberikan selama perkuliahan. Selain itu, dalam menyampaikan argumen atau menjelaskan ide, strategi penyelesaian atau jawaban yang diperoleh juga tidak terlalu baik.

Untuk mengetahui kemampuan komunikasi matematis mahasiswa secara terukur maka dikembangkan instrumen tes berupa soal-soal yang mengharuskan mahasiswa menggunakan kemampuan komunikasi tertulisnya. Hal tersebut didasarkan pada hasil Penelitian Teledahl (2016) yang mengungkapkan bahwa komunikasi tertulis secara tradisional telah digunakan dalam penilaian pengetahuan matematika. Namun, soal-soal yang khusus dirancang untuk melatih kemampuan komunikasi mahasiswa masih sangat terbatas. Oleh karena itu, dalam penelitian ini, dikembangkan instrumen tes kemampuan komunikasi matematis sebagai alat untuk mengukur sejauh mana kemampuan komunikasi matematis mahasiswa calon guru matematika. selain itu, instrumen tes yang dikembangkan dapat menambah khasanah soal-soal khususnya untuk materi sistem persamaan linear pada mata kuliah aljabar linier elementer.

\section{METODE PENELITIAN}

Metode penelitian menggunakan model penelitian \& pengembangan (research and development). Berdasarkan langkah penelitian model ADDIE dari Branch (2009), tahap pengembangan terdiri dari lima tahapan, yaitu: (a) analyze, (b) design, (c) develop, (d) implement, dan (e) evaluate. Pada penelitian ini, dilakukan hanya sampai tahap ketiga yaitu develop (pengembangan).

Tahap pertama adalah analyze. Pada tahap ini dilakukan telaah terhadap tes pengukuran kemampuan komunikasi 
matematis yang sudah ada. Qohar (2011) telah mengembangkan tes uraian untuk mengukur kemampuan komunikasi matematis, tetapi tes uraian tersebut dibuat berdasarkan materi siswa SMP kelas IX. Selain itu, Ismarwan, Bambang, \& Hamdani (2014) juga telah mengembangkan tes kemampuan komunikasi matematis tetapi pada materi siswa kelas VIII SMP, dan Safitri, Dede, \& Bistari (2017) pada materi geometri SMP. Tes komunikasi matematis yang berkaitan dengan materi Sistem Persamaan Linier (SPL) untuk mahasiswa calon guru matematika masih belum ada. Oleh karena itu dilakukan pengembangan tes kemampuan komunikasi matematis materi sistem persamaan linier di mata kuliah aljabar linier elementer (ALE) untuk mahasiswa calon guru matematika.

Tahap kedua adalah design. Pada tahap ini dilakukan pembuatan kisi-kisi tes kemampuan komunikasi matematis mahasiswa calon guru matematika. Kisikisi yang dibuat didasarkan pada indikator yang dikemukakan oleh Sumarmo (2010) yaitu kemampuan menyatakan dan mengilustrasikan ide matematika ke dalam bentuk model matematika yaitu berupa bentuk persamaan, notasi, gambar dan grafik, atau sebaliknya.

Tahap ketiga adalah develop. Kisi-kisi tes yang telah dibuat dikembangkan menjadi soal uraian. Tes kemampuan komunikasi matematis dikembangkan berdasarkan aspek kemampuan mahasiswa dalam mengungkapkan kemampuan komunikasi matematisnya secara tertulis dalam permasalahan matematika. Terdapat lima butir soal uraian yang dikembangkan dalam penelitian ini. Adapun kisi-kisi tes ditunjukkan pada Tabel 1.

Selanjutnya tes yang telah selesai dikembangkan kemudian divalidasi. Proses validasi dilakukan oleh dua orang doktor pendidikan matematika yang berasal dari Universitas Sriwijaya dan Universitas Muhammadiyah Palembang dan satu orang magister matematika murni tentang isi dan muka dari soal tes komunikasi matematis. Menurut Pradana, Parno, \& Handayanto, (2017) didalam memvalidasi isi dan muka terdapat aspek-aspeknya masing-masing. Validasi isi meliputi dua aspek, yaitu: (1) kesesuaian butir soal dengan indikator yang telah dipilih, (2) tingkat kesukaran butir soal (konsep soal). Sedangkan validasi muka meliputi dua aspek, yaitu: (1) penggunaan bahasa dalam butir soal, dan (2) kebenaran konsep kunci jawaban. Hasil validasi yang dilakukan oleh para ahli kemudian analisis dengan uji statistik Q-Cochran. Uji tersebut digunakan untuk mengetahui apakah para ahli melakukan penilaian instrumen secara sama atau tidak (Qohar, 2011). Selain itu, butir soal tes juga direvisi berdasarkan saran dari ahli.

Tabel 1. Kisi-Kisi Tes Kemampuan Komunikasi Matematis

\begin{tabular}{llc}
\hline \multicolumn{1}{c}{$\begin{array}{c}\text { Aspek Kemampuan } \\
\text { Komunikasi Matematis }\end{array}$} & \multicolumn{1}{c}{ Indikator } & $\begin{array}{c}\text { Nomor } \\
\text { Soal }\end{array}$ \\
\hline $\begin{array}{l}\text { Menyatakan dan } \\
\text { mengilustrasikan ide } \\
\text { matematika ke dalam bentuk } \\
\text { model matematika yaitu } \\
\text { bentuk persamaan, notasi, } \\
\text { gambar dan grafik, atau }\end{array}$ & $\begin{array}{l}\text { Menyatakan grafik yang diberikan ke dalam bentuk } \\
\text { persamaan dan menyelesaikannya }\end{array}$ & $\begin{array}{l}\text { Menyatakan permasalahan yang diberikan ke dalam } \\
\text { bentuk model dan persamaan matematika, kemudian }\end{array}$ \\
$\begin{array}{ll}\text { mebaliknya kemudian } \\
\text { menyelesaikannya }\end{array}$ & $\begin{array}{l}\text { Menyatakan permasalahan yang diberikan ke dalam } \\
\text { bentuk model matematika, kemudian menjelaskan }\end{array}$ & 3 \\
\hline
\end{tabular}


penjelasan secara matematis

Menyatakan permasalahan yang diberikan ke dalam 4 bentuk model matematika yang berbentuk persamaan dan menyelesaikannya

Menyatakan suatu gambar menjadi ide atau masalah 5 matematika yang berkaitan dengan SPL Kemudian menyelesaikannya.

Setelah dilakukan tahap revisi, maka dilakukan uji reliabilitas terhadap soal yang telah dikembangkan. Pengujian reliabilitas ini dilakukan dengan mengujicobakan instrumen ke mahasiswa calon guru matematika angkatan 2014 yang dipilih secara acak sebanyak 30 orang. Reliabilitas butir soal dianalisis dengan menggunakan perhitungan koefisien Cronbach's Alpha. Setelah dilakukan uji validitas dan reliabilitas, selanjutnya dilakukan uji daya pembeda butir soal dan analisis tingkat kesukaran butir soal.

Data hasil ujicoba kemudian digunakan untuk menguji daya pembeda butir soal dengan menggunakan rumus (Arikunto, 2013):

$$
D P=\frac{B_{A}}{J_{A}}-\frac{B_{B}}{J_{B}}
$$

Keterangan:

$D P$ : Daya Pembeda

$B_{A}$ : Banyak mahasiswa kelompok atas yang menjawab soal itu dengan benar

$B_{B}$ : Banyak mahasiswa kelompok bawah yang menjawab soal itu dengan benar

$J_{A}:$ Banyak mahasiswa kelompok atas

$J_{B}$ : Banyak mahasiswa kelompok bawah

Sedangkan tingkat kesukaran butir soal menggunakan rumus (Arikunto, 2013):

Keterangan:

$$
P=\frac{B}{J S}
$$

$P \quad$ : Indeks Kesukaran

$$
\begin{array}{ll}
B \quad & \text { banyak mahasiswa yang } \\
& \text { menjawab soal dengan benar } \\
J S & \text { : Jumlah seluruh mahasiswa } \\
& \text { peserta uji coba }
\end{array}
$$

\section{HASIL PENELITIAN DAN PEMBAHASAN}

Proses awal pengembangan tes kemampuan komunikasi matematis ini dengan melakukan analisis (analyze) terhadap tes kemampuan komunikasi matematis yang pernah dikembangkan. Berdasarkan hasil analisis tersebut diketahui bahwa belum ada instrumen tes kemampuan komunikasi matematis yang dikembangkan untuk mahasiswa calon guru matematika khususnya pada mata kuliah Aljabar Linear Elementer (ALE) materi sistem persamaan linier.

$$
\text { Selanjutnya, dilakukan }
$$

penyusunan kisi-kisi instrumen tes pada tahap design. Kisi-kisi instrumen tes tersebut terdiri dari aspek komunikasi matematis yang akan diukur, indikator, dan nomor soal. Berdasarkan kisi-kisi instrumen tes tersebut dikembangkan soal-soal tes berbentuk uraian sebanyak lima soal. Setelah proses pengembangan selesai, dilakukan validasi isi untuk mendapatkan penilaian dan saran perbaikan dari validator. Validator melakukan validasi menggunakan lembar penilaian dengan nilai 1 untuk kategori valid dan nilai 0 untuk kategori tidak valid. Hasil penilaian para ahli dapat dilihat pada Tabel 2 dan Tabel 3. 
Tabel 2. Hasil Validasi Isi Tes Komunikasi Matematis

\begin{tabular}{|c|c|c|c|}
\hline \multirow{2}{*}{$\begin{array}{c}\text { Nomor } \\
\text { Soal }\end{array}$} & \multicolumn{3}{|c|}{ Ahli } \\
\cline { 2 - 4 } & 1 & 2 & 3 \\
\hline 1 & 1 & 1 & 1 \\
\hline 2 & 1 & 1 & 1 \\
\hline 3 & 1 & 1 & 1 \\
\hline 4 & 1 & 1 & 1 \\
\hline 5 & 1 & 1 & 0 \\
\hline
\end{tabular}

Keterangan: 0 = Tidak Valid, $1=$ Valid

Tabel 3. Hasil Validasi Muka Tes Komunikasi Matematis

\begin{tabular}{|c|c|c|c|}
\hline \multirow{2}{*}{$\begin{array}{c}\text { Nomor } \\
\text { Soal }\end{array}$} & \multicolumn{3}{|c|}{ Ahli } \\
\cline { 2 - 4 } & 1 & 2 & 3 \\
\hline 1 & 1 & 1 & 1 \\
\hline 2 & 1 & 0 & 1 \\
\hline 3 & 1 & 1 & 1 \\
\hline 4 & 1 & 1 & 0 \\
\hline 5 & 1 & 1 & 1 \\
\hline
\end{tabular}

Keterangan: 0 = Tidak Valid, $1=$ Valid

Selanjutnya, hasil validasi tersebut dianalisis menggunakan uji statistik QCochran dengan bantuan Statistical Package fo Social Sciences (SPSS) v. 22. Hasil uji statistik disajikan dalam Tabel 4 dan Tabel 5.

Tabel 4. Hasil Uji Q-Cochran tentang Validitas Isi Tes Komunikasi Matematis

\begin{tabular}{|l|r|}
\hline $\mathrm{N}$ & 5 \\
\hline Cochran's $Q$ & $2,000^{\mathrm{a}}$ \\
\hline Df & 2 \\
\hline Asymp. Sig. &, 368 \\
\hline
\end{tabular}

a. 1 is treated as a success.

Sumber: pengolahan data

Tabel 5. Hasil Uji Q-Cochran tentang Validitas Muka Tes

Komunikasi Matematis

\begin{tabular}{|l|r|}
\hline $\mathrm{N}$ & 5 \\
\hline Cochran's $Q$ & $1,000^{\mathrm{a}}$ \\
\hline$d f$ & 2 \\
\hline Asymp. Sig. &, 607 \\
\hline
\end{tabular}

a. 1 is treated as a success.
Berdasarkan hasil pengujian pada Tabel 4 dan Tabel 5 terlihat bahwa nilai statistik Q-Cochran untuk validitas isi dan validitas muka tes komunikasi matematis yang dikembangkan adalah 2,000 dan 1,000 dengan nilai signifikansi 0,368 dan 0,607. Karena nilai signifikansi untuk kedua hasil uji tersebut lebih besar dari 0,05 maka dapat disimpulkan bahwa pada taraf signifikansi 5\% para ahli memberikan penilaian secara sama terhadap validitas isi dan validitas muka pada butir soal tes komunikasi matematis yang telah dikembangkan.

Saran dari ahli yang diperoleh adalah mengenai tingkat kesukaran soal dan perbaikan kalimat soal. Untuk lebih jelasnya dapat dilihat pada Tabel 6 .

Tabel 6. Saran Ahli dari Hasil Validasi

\begin{tabular}{cl}
\hline Butir Soal & \multicolumn{1}{c}{ Saran Ahli } \\
\hline 2 dan 4 & $\begin{array}{l}\text { Kalimat soal diperbaiki agar } \\
\text { tidak ambigu }\end{array}$ \\
5 & $\begin{array}{l}\text { Tingkat kesukaran soal } \\
\text { disesuaikan dengan jenjang } \\
\text { mahasiswa. }\end{array}$ \\
\hline
\end{tabular}

Setelah mendapatkan saran dari ahli dan hasil validasi, dilakukan revisi terhadap butir soal tes. Contoh revisi terhadap butir soal dapat dilihat pada Gambar 1. Selanjutnya, Untuk mengetahui tingkat keajegan saat digunakan untuk mengukur kemampuan komunikasi matematis mahasiswa maka dilakukan uji reliabilitas instrumen. 


\begin{tabular}{|c|c|}
\hline \multicolumn{2}{|l|}{ Soal Nomor 2} \\
\hline $\begin{array}{l}\text { Dasar pertanyaan } \\
\text { (stimulus) }\end{array}$ & $\begin{array}{l}\text { Gamber gambar: www.eastjavatraveler.com } \\
\text { Gambar } 2 . \\
\text { Sebuah Restoran mempunyai } 60 \text { meja yang terdiri dari } 2 \\
\text { tipe. Tipe pertama untuk } 4 \text { orang pada tiap meja dan } \\
\text { tipe kedua untuk } 6 \text { orang seperti yang terlihat pada } \\
\text { Gambar 2.a dan gambar 2.b. Setiap hari minggu siang } \\
\text { restoran tersebut penuh dengan pengunjung } 290 \text { orang. }\end{array}$ \\
\hline Pokok Soal & $\begin{array}{l}\text { Buatlah model matematika dari permasalahan tersebut, } \\
\text { lalu bentuk persamaan dari model matematika yang } \\
\text { telah dibuat agar dapat menentukan banyaknya masing- } \\
\text { masing tipe meja di restoran tersebut, kemudian } \\
\text { selesaikanlah model yang telah kamu buat! }\end{array}$ \\
\hline \multicolumn{2}{|l|}{ Revisi Soal Nomor 2} \\
\hline \begin{tabular}{|l|}
$\begin{array}{l}\text { Dasar pertanyaan } \\
\text { (stimulus) }\end{array}$ \\
\end{tabular} & $\begin{array}{l}\text { Sumber gambar: www.eastjavatraveler.com } \\
\text { Gambar di atas menunjukkan } 2 \text { tipe meja beserta } \\
\text { beberapa kursi pada sebuah restoran. Meja tipe pertama } \\
\text { Restuk } 4 \text { orang dan meja tipe kedua unthu } 6 \text { orang. } \\
\text { minggu siang restoran tersebut penuh dengan } \\
\text { pengunjung sebanyak } 290 \text { orang. }\end{array}$ \\
\hline Pokok Soal & $\begin{array}{l}\text { Buatlah model matematika dari permasalahan tersebut, } \\
\text { lalu bentuk persamaan dari model matematika yang } \\
\text { telah dibuat agar dapat menentukan banyaknya masing- } \\
\text { masing tipe meja di restoran tersebut, kemudian } \\
\text { selesaikanlah model yang telah kamu buat! }\end{array}$ \\
\hline
\end{tabular}

Gambar 1. Contoh Revisi dari Hasil Validasi

Instrumen tes diberikan kepada 30 mahasiswa angkatan 2014 yang dipilih secara acak untuk dikerjakan selama 90 menit. Hasil ujicoba tersebut dianalisis berdasarkan rubrik penskoran kemampuan komunikasi matematis yang dirumuskan oleh Sumarmo (2016). Setelah dianalisis, diperoleh data uji coba instrumen tes kemampuan komunikasi mahasiswa. Untuk menguji reliabilitasnya, dilakukan dengan bantuan aplikasi SPSS for windows v.22. Berdasarkan hasil pengujian tersebut diketahui bahwa nilai koefisien Cronbach's Alpha sebesar 0,708. Menurut Rusman (2013) instrumen dianggap memiliki tingkat reliabel yang tinggi jika nilai Cronbach's Alpha $(r)>$ 0,60 . Oleh karena itu, instrumen tes kemampuan komunikasi matematis mahasiswa calon guru matematika yang dikembangkan memiliki tingkat reliabel yang tinggi.

\section{6 | AKSIOMA}

Jurnal Pendidikan Matematika FKIP Univ. Muhammadiyah Metro 
Setelah instrumen tes memenuhi kriteria valid dan reliabel, selanjutnya dilakukan uji daya pembeda dan tingkat kesukaran butir soal dengan menggunakan data hasil ujicoba kepada 30 orang mahasiswa.

Uji daya pembeda dilakukan untuk melihat kemampuan suatu soal dapat membedakan antara siswa yang memiliki kemampuan tinggi dengan siswa yang memiliki kemampuan rendah (Sundayana: 2014). Hasil dari pengujian tersebut dapat dilihat pada Tabel 7. Berdasarkan tabel tersebut diketahui bahwa terdapat 3 soal yang mempunyai daya pembeda kategori baik sedangkan 2 soal mempunyai daya pembeda dengan kategori cukup.

Tabel 7. Hasil Perhitungan dan Interpretasi Daya Pembeda Butir Soal Komunikasi Matematis

\begin{tabular}{ccc}
\hline Nomor Soal & Daya Pembeda & Interpretasi \\
\hline 1 & 0,344 & Sedang \\
2 & 0,406 & Baik \\
3 & 0,469 & Baik \\
4 & 0,313 & Sedang \\
5 & 0,468 & Baik \\
\hline \multicolumn{3}{c}{ Sumber: pengolahan data }
\end{tabular}

Uji tingkat kesukaran butir soal dilakukan untuk melihat apakah suatu soal dipandang sulit, sedang, atau mudah dalam mengerjakannya (Sundayana, 2014). Berdasarkan hasil pengujian tingkat kesukaran butir soal diperoleh informasi bahwa kelima butir soal yang telah dikembangkan masuk kategori soal sedang. Hasil perhitungannya dapat dilihat pada Tabel 8.
Tabel 8. Hasil Perhitungan dan Interpretasi Tingkat Kesukaran Butir Soal Komunikasi Matematis

\begin{tabular}{ccc}
\hline $\begin{array}{c}\text { Nomor } \\
\text { Soal }\end{array}$ & Tingkat Kesukaran & Interpretasi \\
\hline 1 & 0,475 & Sedang \\
2 & 0,416 & Sedang \\
3 & 0,375 & Sedang \\
4 & 0,442 & Sedang \\
5 & 0,458 & Sedang \\
\hline \multicolumn{3}{c}{ Sumber: pengolahan data }
\end{tabular}

Instrumen tes yang telah valid dan reliabel, serta diketahui daya pembeda dan tingkat kesukarannya kemudian dapat digunakan untuk mengukur kemampuan komunikasi matematis mahasiswa calon guru matematika.

\section{KESIMPULAN DAN SARAN}

Berdasarkan hasil penelitian dan analisis data, diketahui bahwa lima butir soal yang telah dikembangkan memiliki kategori valid. Tingkat reliabiltas Cronbach Alpha dari soal yang valid tersebut adalah 0,708. Hal ini berarti bahwa kelima butir soal tersebut memiliki reliabilitas tinggi, sehingga dapat digunakan untuk mengukur kemampuan komunikasi matematis mahasiswa secara valid dan reliabel. Selain itu, kelima butir soal tes tersebut memiliki daya pembeda yang cukup baik. Sedangkan, tingkat kesukaran dari kelima soal yang dikembangkan memiliki kategori sedang.

Penelitian ini hanya sampai tahap pengembangan soal saja dan belum sampai pada tahap implementasi. Sehingga perlu dilakukan penelitian lanjutan dengan menggunakan soal yang telah dikembangkan untuk mengetahui sejauh mana kemampuan komunikasi matematis mahasiswa calon guru matematika saat ini. 


\section{DAFTAR PUSTAKA}

Arikunto, S. (2013). Dasar-Dasar Evaluasi Pendidikan. Jakarta: Bumi Aksara.

Branch, R. M. (2009). Instructional Design: The ADDIE Approach. New York: Springer New York.

Ismarwan., B. H., \& Hamdani. (2014). Kemampuan Komunikasi Matematis Siswa dalam Materi Sistem Persamaan Linear Dua Variabel di Kelas VIII SMP. Jurnal Pendidikan dan Pembelajaran, Vol. 3, No. 2, Hal $1-10$

Nayazik, A., \& Arie, W. (2017). Peningkatan Kemampuan Komunikasi Matematis Mahasiswa Melalui Model Ideal Problem Solving dalam Aspek Gramatika dan Sosiolinguistik. Jurnal Didaktik Matematika. Vol. 4 No. 2, Hal. 107-114

Pradana, S. D. S., Parno, P., \& Handayanto, S. K. (2017). Pengembangan Tes Kemampuan Berpikir Kritis pada Materi Optik Geometri untuk Mahasiswa Fisika. Jurnal Penelitian dan Evaluasi Pendidikan. Vol. 21, No. 1, Hal 51-64

Qohar, A. (2011). Pengembangan Instrumen Komunikasi Matematis Untuk Siswa SMP. http://eprints.uny.ac.id/6968/1/ Makalah\%20Peserta\%204\%20$\% 20 \quad$ Abd.\%20Qohar2.pdf, diakses 25 Juli 2018.

Rusman, T. (2013). Statistika Ekonomi. Bandar Lampung: Unila.

Safitri, E., Dede S., \& Bistari. (2017). Pengembangan Instrumen untuk Mengukur Kemampuan repserenstasi dan Komunikasi
Matematis Siswa dalam Aspek Fonetik Materi Geometri SMP. Jurnal Pendidikan dan Pembelajaran, Vol. 6, No. 9, Hal 1-14

Son, A. L. (2015). Pentingnya Kemampuan Komunikasi Matematika Bagi Mahasiswa Calon Guru Matematika. Gema Wiralodra. Vol. VII No. 1, Hal. 18

Sumarmo. U. (2010). Berfikir dan Disposisi Matematik: Apa, Mengapa, dan Bagaimana Dikembangkan pada Peserta Didik. Makalah diterbitkan oleh Suryadi, D, Turmudi, Nurlaelah, E. (Editors). Kumpulan Makalah Proses Berpikir dan Disposisi Matematik dan Pembelajarannya. 2014. Hal. 75-89.

Sumarmo. U. (2016). Pedoman Pemberian Skor Pada Beragam Tes Kemampuan Matematika. http://utari-

sumarmo.dosen.stkipsiliwa ngi.ac.id/files/2016/05/PedomanPemberian-Skor-Tes-Kemampuan -Berpikir-Matematik-dan-MPP2016-1.pdf. diakses tanggal 10 februari 2018.

Sundayana, R. (2014). Statistika Penelitian Pendidikan. Bandung: Alfabeta.

Teledahl, A. (2016). How young students communicate their mathematical problem solving in writing. International Journal of Mathematical Education in Science and Technology. Vol. 48 No. 4, Hal. 555-572

Uptegrove, E. B. (2015). Shared communication in building mathematical ideas: A longitudinal study. The Journal of 
ISSN 2089-8703 (Print) Vol. 7, No. 2 (2018) 291-299

ISSN 2442-5419 (Online)

Mathematical Behavior, 40, Part A, 106-130.

Widjajanti, D.B., \& Wahyudin. (2010). Mengembangkan Kemampuan Komunikasi Matematis Mahasiswa Calon Guru Matematika melalui Strategi Perkuliahan Kolaboratif Berbasis Masalah. Makalah KNM 2010. http://staff.uny.ac.id/sites/ default/files/131569335/Makalah \%20KN M\%20DJAMILAH\%20 UN Y.pdf
Yuniarti, Y. (2014). Pengembangan Kemampuan Komunikasi Matematis dalam Pembelajaran Matematika di Sekolah Dasar. Jurnal Pendidikan Dasar: Eduhumaniora. Vol. 6 No. 2, Hal. 109-114 